\title{
CENTRAL BANK COMMUNICATION IN THE PAST TWO DECADES. THE ECB'S EXPERIENCE
}

\author{
by Thierry Bracke
}

\section{Introduction}

In the mid-1980s, journalist and author William Greider argued that the U.S. secret services were more transparent than the central bank. In a book with a telling title, "Secrets of the temple: How the Federal Reserve Runs the Country", he argued that the Federal Reserve, while concentrating considerable power, was hardly communicating and was not really held to account on its actions.

Greider's assessment was forceful, perhaps excessive. But it did reflect a prevailing perception in the 1980s that central banks - not just in the United States, but across the world - were rather closed and secretive. Reports, books and academic research at the time zoomed in on central bank secrecy, not on transparency. Goodfriend ${ }^{1}$, for instance, reviewed under which conditions monetary policy secrecy could be socially beneficial. To be clear, authors such as Goodfriend did not unequivocally defend secrecy. Actually, quite to the contrary, most of them called for increasing transparency. But it is striking that research questions until some thirty years ago were framed in terms of finding the optimal level of "secrecy" rather than identifying the best standards for "transparency".

European Central Bank.

The views expressed in this Article are solely those of the author and do not necessarily reflect those of the European Central Bank (ECB).

1 M. Goodfriend, Monetary mystique: Secrecy and central banking, in "Journal of Monetary Economics", n. 1, 1986. pp. 63-92. 
Since then, the world of central bank communication has seen a sea change. The literature moved from a focus on optimal levels of central bank secrecy to an analysis of the benefits of communication and transparency. Central banks have gradually stepped up their communication activities. This also applies to the European Central Bank (ECB), which adopted an advanced transparency policy already when the euro was launched in 1999, and since then gradually expanded its communication efforts.

In this article, I will review the reasons underlying this evolution or revolution - of central bank communication, focusing on three trends. The longest-standing trend, which has accompanied central banking roughly since the 1970s and 1980s, is a legitimate increase in the demand for transparency as part of a societal change and as a natural companion to increased central bank independence. A second, more recent, trend is the increasing recognition that communication is not just a response to public demand, but also a key component of a modern monetary policy toolkit. A third trend relates to growing public interest - but also growing public criticism - in institutions in general and central banks in particular, which became particular intensive in the aftermath of the crisis that started in 2008. I will discuss these three trends in turn, illustrating what they concretely implied for the ECB.

\section{Institutional trends towards increased central bank transparency}

Historically, communication was not a hallmark of central banking. Haldane ${ }^{2}$ anecdotally reports that the Bank of England Governor would deliver one speech a year until the 1960s. Sometimes, central banks did not even share "basic" information about their decisions. As late as 1994, the Federal Reserve did not announce its interest rate decisions and instead left it to markets to infer target rates from its market interventions ${ }^{3}$. Nowadays, this appears unthinkable as most major central banks not only announce, but also explain, monetary policy decisions

2 A.G., Haldane, A Little More Conversation A Little Less Action, Bank of England, 2017.

3 See the opinion piece published by M. DraghI, Central Bank Communication, in "Handelsblatt", 4 August 2014. 
via statements or press releases, publications, and, in some cases, press conferences.

The trend towards increased central bank transparency is a global phenomenon and has been amply captured in surveys and reviews. For example, an index compiled by Dincer and Eichengreen ${ }^{4}$ suggests that the level of central bank transparency has shifted upwards since the late-1990s across advanced, emerging and developed countries. The index captures the extent of public information about central banks mandates and objectives, the information used for monetary policy, the decision-making processes and the actual decisions taken.

One explanation for this trend is a wider societal trend of increased transparency among public institutions. Citizens expect their public administrations to hold up high standards in terms of efficiency, fairness and integrity. Access to timely information about policymakers' objectives, policies and processes forms an integral part of this. Armstrong 5 notes that the "values of integrity, transparency and accountability in public administrations have enjoyed a resurgence within the past three decades". Public sector transparency is also an element of democratic accountability and a potential driver of economic performance. Transparency is indeed usually found to be positively correlated with economic performance, and a number of studies point to a causal impact, as more clarity on public policies tends to improve planning certainty for economic agents ${ }^{6}$. Over the past decades, central banks have followed the general trend of increased openness in public administrations. Based on an econometric analysis of the determinants of central bank transparency, Dincer and Eichengreen ${ }^{7}$ find that transparent monetary policy arrangements "are more likely in democracies, with their culture of transparency."

4 N. Dincer, B. Eichengreen, Central Bank Transparency and Independence: Updates and New Measures, in "International Journal of Central Banking", n. 1, 2014, pp. 189-259.

5 E. ARMSTRONG, Integrity, transparency and accountability in public administration: Recent trends, regional and international developments and emerging issues, NewYork, United Nations, Department of Economic and Social Affairs, 2005, pp. 1-10.

6 See e.g. R.G. Gelos, S.J.WeI, Transparency and international portfolio holdings, in "The Journal of Finance", n. 6, 2005, pp. 2987-3020.

7 N. Dincer, B. Eichengreen, Central bank transparency: causes, consequences and updates, in "Theoretical Inquiries in Law", n. 1, 2010, pp. 75-123. 
A further explanation for increased central bank transparency is that greater openness acts as a natural companion of increased monetary policy discretion. Monetary policy historically tended to be relatively constrained by a so-called operational mandate in many jurisdictions. Whether under the gold standard, the Bretton Woods system, or the European exchange rate mechanism (ERM), central banks typically followed a rather strict set of rules, anchoring their policies to gold, to the Us dollar or (de facto) to the Deutsche mark. Under such regimes, the successful execution of monetary policy could be gauged rather easily by specialists and by the general public alike through a simple monitoring of the success in following the rule. Hence there was no strong need for continuous explanations of policy frameworks or policy decisions.

This changed over time as several countries shifted to floating exchange rate regimes following the collapse of the Bretton Woods system and central banks increasingly pursued a goal mandate, defined for instance in terms of price stability, while being left with considerable discretion to make that mandate operational. Under a goal mandate, central banks had to go to greater lengths to announce their operational targets and explain the decisions taken to meet those targets. According to Dincer and Eichengreen ${ }^{8}$, increased monetary policy transparency and the shift towards a goal mandate over the past decades were not just correlated, but actually causally related.

Moreover, transparency and accountability also became more important as natural counterparts of increased central bank independence. Central banks across a wide range of countries gained increasing independence since the $1980 \mathrm{~s}^{9}$. A broad consensus exists in the literature that legal, personal, operational and financial independence, coupled with a price stability mandate, are conducive to credibly anchoring monetary policy, assuring price stability and overcoming time-consis-

8 N. Dincer, B. Eichengreen, Central bank transparency: causes, consequences and updates, cit..

9 C. Crowe, E.E. Meade, Central bank independence and transparency: Evolution and effectiveness, in "European Journal of Political Economy", n. 4, 2008, pp. 763-777; A. Cukierman, G.P. Miller, B. Neyapti, Central bank reform, liberalization and inflation in transition economies - an international perspective, in "Journal of Monetary Economics”, n. 2, 2002, pp. 237-264, N. Dincer , B. Eichengreen, Central Bank Transparency and Independence: Updates and New Measures, cit.. 
tency problems in monetary policy ${ }^{10}$. With increased independence came also a trend towards more transparency and a clear accountability framework. This is covered in detail by Giovannini and Jamet ${ }^{11}$.

The ECB's institutional framework has been framed by these global trends. To start with, its institutional design as set out in the early-1990s in the Maastricht Treaty is based on a price-stability oriented mandate and a clear set of provisions on independence ${ }^{12}$. This reflected a broadly prevailing international consensus on the benefits of a clear central bank mandate and strong central bank independence. It was also inspired by the positive German experience with a central bank geared towards price stability and operating independently.

In line with the considerations above about the mutual reinforcement between a price stability mandate, central bank independence and transparency, it is therefore not surprising that the $\mathrm{ECB}$, from the very launch of its monetary policy operations in 1999, followed a pro-active transparency policy. In fact, the ЕСB has a number of Treaty-based reporting requirements, including the production of an annual report, a quarterly report on its activities ${ }^{13}$, a weekly financial statement and a convergence report ${ }^{14}$. Even if these reporting obligations seem fairly minimal and belong to the standard toolkit of nearly every central bank nowadays, it is quite unique that they are embedded in a legal requirement at quasi "constitutional" level.

But the ECB, from the outset, decided to go beyond its legally pre-

10 See O. Issing, Central Bank Independence-Economic and Political Dimensions, in "National Institute Economic Review", n. 1, 2006, pp. 66-76 for a discussion of empirical and theoretical considerations on the benefits of central bank independence. For theoretical foundations on the time-consistency problem in monetary policy, see F.E. Kydland, E.C. Prescott, Rules rather than discretion: The inconsistency of optimal plans in "The journal of political Economy", 2006, pp. 473-491; R.J. BARRO, D.B.GoRDON, Rules, discretion and reputation in a model of monetary policy, in "Journal of monetary economics", n. 1, 1983 pp. 101-121.

11 A. GIOVANNINI, J.-F. JAMET Matching accountability with independence: the ECB'S experience in the same issue of this journal "Il Politico", n. 1, 2020, pp. 103-121.

12 On the ECB's primary objective, see Art 127.1 TFEU and Art. 2 of the ECB statute. On the ECB's independence, see Art. 130 TFEU and Art. 7 of the ESCB statute.

13 The ECB went beyond the required quarterly reporting by publishing a report on a monthly basis until 2014 (Monthly Bulletin) and on a six-weekly basis since 2015 (Economic Bulletin).

14 The ECB's reporting requirements are set out in Art. 15 of the $\mathrm{ESCB}$ statute. 
scribed reporting requirements and started providing information on:

- its objectives, notably by defining and quantifying its price stability objective ${ }^{15}$;

- its monetary policy framework, covering both the analysis used to inform monetary policy decisions and the operational framework for monetary policy implementation;

- its monetary policy decisions and the rationale underlying those decisions, which from the start were explained at press conferences immediately following the monetary policy meetings, initially at monthly, later at six-weekly, intervals.

In particular the organisation of monthly press conferences immediately after monetary policy meetings was seen at the time as a bold move, bringing the ECB ahead of the curve in terms of transparency.

Since then, the ЕСв has gone beyond that, with a number of changes including:

- the publication of quarterly staff macroeconomic projections on growth and inflation, which started in 2004 and have been expanded over time, with most recently (in 2016) an addition of a breakdown by country;

- the release of additional analysis, including through various reports and publications such as the Financial Stability Review (as of 2004);

- the dissemination of an increasing number of statistical data, which are freely available and reusable.

The ECB also gradually enhanced transparency around decisionmaking, information gathering and governance. For instance, starting in the 2015, the ECB published accounts of the Governing Council's monetary policy discussions, providing additional information on the rationale behind monetary policy decisions and on the Governing Council's assessment within a short period of time after the discussion. Other changes in recent years include the release of "Guiding Principles for external communication by members of the Executive Board",

15 Price stability was defined by the ECB's Governing Council in October 1998 as follows: "Price stability shall be defined as a year-on-year increase in the Harmonised Index of Consumer Prices (HICP) for the euro area of below $2 \%$. Price stability is to be maintained over the medium term". This was further clarified in May 2003, when the Governing Council indicated that it "aims to maintain HICP inflation below but close to $2 \%$ over the medium term". 
which codify a number of principles for communication, the monthly publication of diaries of the Executive Board Members and the Chair of the Supervisory Board, and the release of agendas and summaries of high-level meetings with a number of stakeholders, such as the Institutional Investor Dialogue and the Banking Industry Dialogue ${ }^{16}$.

\section{Communication as a monetary policy tool}

In the previous section, I argued that central bank transparency increased over time as a result of institutional drivers justifying an increased public interest in central banks explaining their objectives, processes and decisions. In this section, I will argue that communication additionally has become an essential monetary policy tool. Nowadays, successful monetary policy without effective communication is hardly thinkable.

In a central banking world with constraining monetary policy rules such as exchange rate pegs, communication was not quintessential in determining inflation paths and policy outcomes. Using a somewhat stretched comparison, setting monetary policy was like a driving a car: to determine the car's speed and direction, it is sufficient to act on the gas pedal and the steering wheel. The driver does not need to talk to the gas pedal or explain his or her intentions to the steering wheel.

This changed as monetary policy became more goal-oriented and increasingly complex, a trend that was further compounded by deepening financial markets and a concomitant increase in the complexity of monetary policy transmission channels. By now, it is widely acknowledged that "central bank communication is right at the heart of monetary policy. It is actually a monetary policy tool in itself" 17 .

Of particular relevance for monetary policy communication is that price developments are not only shaped by current interest rates and current economic conditions, but also by expectations about future rates and future economic conditions. In his foundational review of monetary

${ }^{16}$ See B. CEuré, Independence and accountability in a changing world. Introductory remarks at the Transparency International EU Event "Two sides of the same coin? Independence and accountability of the European Central Bank", 2017.

${ }^{17}$ M. Draghi, Central Bank Communication, cit.. 
policy, Woodford 18 argues that "successful monetary policy is not so much a matter of effective control of overnight interest rates as it is of shaping market expectations of the way in which interest rates, inflation, and income are likely to evolve over the coming year and later." Blinder et al. ${ }^{19}$ point to a growing consensus that "monetary policy is, at least in part, about managing expectations", which they depict as "a revolution in thinking" compared to central banking before the 1990s. This reasoning was very central in the inflation targeting literature, where transparency was not just seen as a nice-to-have feature of central banking, but as a necessary condition for a successful delivery of price stability ${ }^{20}$.

While the growing contribution of communication as a policy tool is a pre-crisis phenomenon, it became even more prominent and visible in the aftermath of the global financial crisis that started in 2008. In a recent survey among central bank governors across the globe, Blinder et al. ${ }^{21}$ find that an "overwhelming majority" of respondents indicated that communication had intensified since the crisis. Most of them saw intensified communication not as a passing phenomenon but expected that it was there to stay as overall economic and financial conditions would normalise.

A key reason for enhanced communication in the aftermath of the crisis was that several central banks started approaching the effective lower bound to interest rates. In particular, as the room for action on current short-term interest rates became more limited with interest rates approaching zero, and as some classical monetary policy transmission channels became impaired, several central banks engaged in unconventional monetary policy instruments. A prominent example are out-

18 M. Woodford, Interest and Prices: Foundations of a Theory of Monetary Policy, Princeton, Princeton University Press, 2003.

19 A.S. Blinder, M. Ehrmann, M. Fratzscher, J. De HaAn, D.J. Jansen, Central bank communication and monetary policy: A survey of theory and evidence in "Journal of Economic Literature", n. 4, 2008, pp. 910-945.

${ }^{20}$ M.D. Laxton, C. Freedman, Inflation Targeting Pillars: Transparency and Accountability, IMF Working Paper, No. 9-262, Washington D.C., International Monetary Fund, 2009.

21 A.S. Blinder, M. Ehrmann, M. Fratzscher, J. De HaAn, D.J. Jansen, Necessity as the mother of invention: monetary policy after the crisis, in "ECB Working Paper Series", 2017, p. 2047. 
right asset purchases, which required new explanations and additional communication efforts. But it also included the deployment of pure communication measures, in particular indications on the expected future policy path. All major central banks in recent years resorted to some form of forward guidance, using formulations that were either open-ended ("for some time", "for an extended period"), time-contingent ("at least until [specific date]") or state-contingent (specification of economic conditions $)^{22}$.

\section{A changing communication landscape}

A third element shaping communication developments is an increasing public interest in central banking, with an intensified - and sometimes polarised - public debate on the role and actions of central banks. Traditionally, it seemed sufficient for central banks to address an audience of specialists in the media, in academics and in financial markets. Explaining monetary policy actions to specialists and analysts was seen as helping shape market reactions and enhancing monetary policy transmission.

The general public historically was not all too interested in central banking, or at least interest appeared to be largely confined to the most tangible central bank product, i.e. banknotes, whereas public knowledge about monetary policy tended to be more limited. The ECB was no different: in the early days of the euro, almost $30 \%$ of European citizens had never even heard of the $\mathrm{ECB}^{23}$. This has changed over time and, by 2016 , this percentage dropped to $15 \%$ according to the European Commission's Eurobarometer. This no doubt in part reflects a greater awareness after almost 20 years of EMU, but it also testifies to

22 In the economic literature, different types of forward guidance are sometimes classified as qualitative, calendar-based, and data-based, following A. Filardo, B. Hofmann, Forward guidance at the zero lower bound, in "International banking and financial market developments", n. 3, 2014, p. 37. For an overview and discussion of forward guidance by the Federal Reserve, ECB, Bank of Japan, Bank of England and Bank of Canada, see e.g. R. Moessner, D.J. JANSEN, J. DE HAAN, Communication about future policy rates in theory and practice: A survey, in "Contemporary Economic Policy", n. 4, 2016, pp. 698-709.

${ }^{23}$ See various issues of the European Commission Eurobarometer data, EU-wide answers to the question "Have you heard of the ECB?". 
the wider trend of central banks getting more in the public limelight. Easier access to information via internet and social media contributed to that. Also, the unconventional measures taken by many central banks triggered greater public attention. A broader discussion on the implications of monetary policy, including its distributional impact, also contributed to that. So did the evolving tasks of central banks, in particular also in the euro area, where the ЕСB took on an advisory role in the context of the EU/IMF adjustment programmes and was assigned banking supervision tasks in 2014. Central banks, including the ECB, were suddenly no longer just distant institutions, but became a topic of public interest and discussion.

Over recent years, central banks started to navigate not only in an environment of increasing public interest, but also one of decreasing public trust. Declining trust is not unique to central banking and instead forms part of a wider societal trend of reduced trust in private and public institutions alike. For instance, when asked whether they trust their national governments, a majority of Eu citizens answered "yes" in the Eurobarometer in the early-2000s, while almost two-thirds answered "no" in the Eurobarometer editions from 2010 onwards. This trend did not halt in front of the central bank doorsteps as all major central banks generally saw a decline in the degree of public confidence or satisfaction ${ }^{24}$.

Central banks have generally responded by stepping up their efforts in explaining their mandates and actions. Such "stepping up" did not just focus on providing an increasing amount of information. In fact, information on central banks tends to be quite ample available. The ECB website is a case in point, as it has over 100,000 pages and documents. The main priority therefore is not necessarily to continuously increase the quantity of information provided, but rather to better structure it and tailor it to meet the needs of audiences.

The point that central bank communication does not necessarily improve by just providing ever more information is also mirrored in the economic literature, which finds that there can be an optimal level of central bank transparency, beyond which further information can be welfare destroying rather than welfare enhancing. As highlighted by

${ }^{24}$ See Chart 12 in A.G. Haldane, A Little More Conversation A Little Less Action, cit., which portrays the development of trust/confidence/satisfaction with major central banks. 
Reis ${ }^{25}$, who reviews some of the literature on optimal central bank transparency, central banks ought to be "as transparent as possible" but there can be circumstances where "central bank announcements foster confusion rather than better understanding." In addition, some authors identify the risk that too much information could drown out the central bank's core messages and add "noise" rather than "clarity". Blinder 26 (2009) points for instance to the "danger of creating a cacophony" when members of a monetary policy committee speak with too many disparate voices.

So, rather than just focusing on increasing the amount of information shared with its key audiences, most major central banks have invested considerably in reviewing the approach, content and channels of its communication.

In terms of approach, a growing but in part still incipient tendency is a shift from one-way communication to two-way engagement. Haldane ${ }^{27}$ makes a strong plea for central banks to start "listening as often as talking". In the central banking domain, direct contact with stakeholders tends to be relatively focused on specialised audiences, for instance through conferences and seminars with academics or analysts. One prime channel for the ECB to engage in a broader two-way dialogue are the hearings held at the European Parliament as elected representatives of the European citizens ${ }^{28}$. Platforms for ECB direct engagement with the general public were initially limited to a few channels, such as a public enquiries function and a visitor's programme. Recently, this has been enriched by the launch of a Visitor Centre in July 2017, which does not take a "learning" approach of an exhibition or a traditional museum but provides a space to engage with visitor groups. Other recent events underlining the ECB's commitment to two-way interaction include a live twitter question and answer session with an ЕСB Executive Board Member in December 2016, a youth dialogue in June 2017,

${ }^{25}$ R. ReIs, Central bank design, in "The Journal of Economic Perspectives", n. 4, 2013, pp. 17-43.

26 A. BLINDER, Talking about monetary policy: the virtues (and vice?) of central bank communication in "Bank for International Settlements Working Papers" n. 274, 2009.

27 A.G. Haldane, A Little More Conversation A Little Less Action, cit..

28 See A. GIOVANNINI and J.-F. JAMET Matching accountability with independence: the ECB's experience, cit.. 
where the ЕСв President engaged in a conversation with an audience of students in Lisbon and addressed questions asked via social media channels, as well as the ЕСВ opening its doors to young children in the context of "Sendung mit der Maus", a German TV series for children.

Regarding content, central banks focused on complementing their traditional analytically oriented work with clearer, shorter and more accessible messages. For instance, the ECB introduced a new "explainer" section on its central banking website in 2015, providing information on very general questions ("What is a central bank?") and specialised central bank domains ("What are minimum reserve requirements?") in a language that aims to avoid jargon and overly complex sentences. A similar section was introduced on the ECB's banking supervision website, under the format "Supervision. Explained." 29.

This is complemented with an increased use of audiovisual material. The ECB has considerably expanded its array of videos, pictures and infographics shared with the general public, complementing the more "traditional" central bank channel of lengthy publications and texts. By way of example, the ECB's 2016 Annual Report was accompanied by a video message of the ЕСB President. One of the Annual Report's special features, focusing on rather inaccessible financial innovation topics such as distributed ledger technology, was enriched with visual illustrations and infographics. In doing so, the ECB aims to make rather complex topics more easily accessible.

In terms of communication channels, most central banks have expanded the range of channels by launching a social media presence. The ECB mainly focused on twitter, with an account that reached over 380,000 followers in the first half of 2017, while it is also present on some other channels, including Flickr, YouTube and LinkedIn. The ECB also invested in improving accessibility and formats used in its traditional communication channels, such as its websites. In 2014, the ECB overhauled the accessibility and presentation of its websites, allowing more easy readability on mobile devices. It also started producing its main publications, including the Economic Bulletin and the Annual Report, in a web-friendly format. This offers readers an attractive al-

${ }^{29}$ See https://www.ecb.europa.eu/explainers/topic/html/index.en.html for the ECB website and https://www.bankingsupervision.europa.eu/about/ssmexplained/html/index. en.html for the banking supervision website. 
ternative to the classical downloading of bulky PDF files and helps improve the searcheability of the wealth of information provided on the ECB website.

While the $\mathrm{ECB}$ has pro-actively engaged in strengthening its engagement with wider audiences, there are also a number of natural limits. One such limit relates to the sheer size of the population and its diversity in terms of languages. With direct outreach activities, the ECB can certainly not reach individually over 340 million citizens, spread across 19 countries. Here, an extremely powerful and helpful institutional feature is that the ЕСВ does not stand alone, but forms part of the Eurosystem together with 19 national central banks in the euro area. Many of those central banks have a long-standing tradition and expertise in contacting non-specialist audiences through visitor programmes, museums, open days, educational activities, visits to schools and universities etc.

\section{Conclusions}

The foundations of the ECB's communications policy were laid as the euro was launched in 1999. At the time, a lot of emphasis was put on explaining the monetary policy framework and the monetary policy decisions taken. This was done through various channels, including through, at that time still very innovative, press conferences held right after the monetary policy meetings.

These key features of the early ECB's communication approach still stand today. But time did not stand still and quite a number of changes occurred throughout the years. As reviewed in this article, the list of new communication initiatives is long and includes various new publications, additional communication channels including social media, enhanced information on meetings (e.g. through the accounts of monetary policy meetings), more easily-accessible and user-friendly communication formats, clearer and simpler language, more infographics and visuals, and strengthened engagement with citizens.

The ECB was not unique in adapting its communication approach over time. Other central banks also engaged in several new communication initiatives over the past two decades. Taken individually, these initiatives point to a clear evolution in central bank communication. Taken together, they constitute a small revolution over a relatively brief 


\section{time span. Clearly, central banks have left the perceived sphere of se- crecy as it prevailed still in the 1980s.}

Riassunto - Sin dagli anni Ottanta del secolo scorso, la comunicazione delle banche centrali ha vissuto un cambiamento radicale. La letteratura è passata da un'attenzione ai livelli ottimali di segretezza delle banche centrali ad un'analisi dei benefici della comunicazione e della trasparenza. Le banche centrali hanno gradualmente intensificato la loro attività di comunicazione. Ciò vale anche per la BCE, che ha adottato una politica di trasparenza avanzata già al momento del lancio dell'euro nel 1999, e da allora ha gradualmente ampliato le sue attività di comunicazione. L'articolo passa in rassegna le ragioni di questa evoluzione - o rivoluzione della comunicazione delle banche centrali, concentrandosi su tre tendenze ed illustrandole con il caso concreto della BCE. La ten- denza di più lunga data, più o meno sin dagli anni Settanta e Ottanta, è un legittimo aumento della domanda di trasparenza come parte di un cambiamento della società e come correlato naturale di una maggiore indipendenza delle banche centrali. Una seconda tendenza, più recente, è la crescente consapevolezza che la comunicazione non è solo una risposta alla domanda del pubblico, ma anche una componente chiave di un moderno kit di strumenti di politica monetaria. Una terza tendenza riguarda il crescente interesse dell'opinione pubblica - ma anche la crescente critica dell'opinione pubblica - nei confronti delle istituzioni in generale e delle banche centrali in particolare, che è diventata particolarmente intensa all'indomani della crisi iniziata nel 2008. 